Testing weak form efficiency of capital markets: A case of Pakistan

Rehman, Sania

National Defence University, Islamabad, Pakistan (maliks_88@hotmail.com)

Qamar, Muhammad Rizwan $\$

National Defence University, Islamabad, Pakistan (mrrizwanqamar@gmail.com)

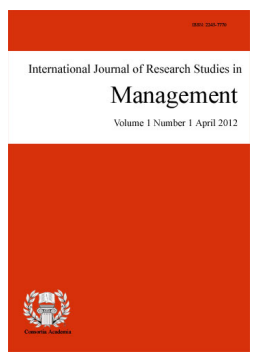

ISSN: $2243-7770$ Online ISSN: 2243-7789

OPEN ACCESS

\title{
Abstract
}

Efficient Market Hypothesis has attracted considerable attentions from researchers of all over the world. A large number of studies have already been conducted by the researchers and a lot of importance has given to the emerging markets. Different studies give different outcomes on market efficiency of the emerging markets. To institute a more perfect conclusion about Market Efficiency in Pakistani financial markets this study is conducted on the major Stock Market of Pakistan such as the Karachi Stock Exchange. Three econometric tests have applied on the daily data of KSE-100 index for two years from 2009 and 2010 including the famous Runs Test, Autocorrelation Function (ACF) test and the Augmented Dickey-Fuller (Unit Root) test. Different tests are applied to form a distinctive opinion on the Weak Form Efficiency of the KSE. The results of this study revealed that there exists a positive correlation in the KSE 100-index. The runs test gives zero p-value which shows continues growing trend. This illustrate that the performance of the market is inefficient. The similar results have been shown in the previous studies on the KSE.

Keywords: autocorrelation; runs test; unit root test; efficient market hypothesis; random walk theory 


\section{Testing weak form efficiency of capital markets: A case of Pakistan}

\section{Introduction}

From the last few years it is now necessary to understand the behavior of the financial markets because of the new invention of the various risk management tools that is used to influence the financial market efficiency that were not used before few decades and now the efficiency of markets is more dynamic and capable than before (Husain, 2011). Fama, (1970) prescribed the theory of market efficiency, structured the experimental indication and categorize the market efficiency into three types namely:

$>\quad$ Weak form efficiency (WFE)

$>\quad$ Semi-strong from efficiency (SSFE)

$>\quad$ Strong form efficiency $(\mathrm{SFE})$

The Efficient Market Hypothesis (EMH) believes that in the accession of new information the stock prices adjust quickly, and consequently, current prices reflects by all existing historical information (Ansari, 2011; Hussain, Hamid, \& Khan, 2011). The weak form efficiency is commonly known as "random walk theory". The market will be weak form efficient contends that, if the currents prices such as: buying \& selling volumes, prices and other market associated information reflects by all prices of historical information (Ansari, 2011; Hussain, Hamid, \& Khan, 2011). The semi-strong form market efficiency states that the prices entirely reflect both historical and all public information which includes non-market information, for instance: earnings, declaration of dividend, monetary and social information. Lastly the strong-form efficiency asserts that all information from past, private and public resources reflects by stock prices, so that not anyone shareholder can acquire abnormal rate of return (Ansari, 2011).

It is frequently consider that the markets in under-developed countries or least-developed countries are not competent in semi-strong form efficiency and strong-form efficiency (Mobarek \& Keasey, 2000). Stock market efficiency is an important concept in terms of an understanding, their performance of the working of stock markets and input in the growth of a country's economy. The prices will signify the intrinsic value of the stock if the stock market is efficient (Ansari, 2011). It is easy to test the weak-form efficiency of the market comparatively semi strong form and strong form. The test of semi-strong and strong form efficiency is infrequent in less developed countries because of deficiency of satisfactory data in a convenient form, lack of administration and managerial loose in the implication of accessible rules and in addition the information of the company which is delivered and spread in market before the annual report available; the annual reports of some of the companies are suspicious and often most of the circulations are rumors in the market about the listed companies. The market now significantly moving and most of the investors in the market becomes broker. Furthermore, the share price of the market indicates data is now presented and consistent to test the weak-form efficiency of the market (Mobarek \& Keasey, 2000).

Every investor divergent manner before investing in particular security they needs to calculate market risk and to calculate this risk they require the evaluation of volatility parameter and they think it as the input key for their strategies. Volatility is described as tendency of the securities or assets price to change either upward or downward. The increased in the volatility indicating that financial risk rise which will affect the investor assets and the investor probably leave the market by losing confidence (Hameed \& Ashraf, 2006).

From the last few decades, the statisticians, economists and finance teachers have been concerned in producing and testing the existence of market weak form efficiency. A major number of studies by using different methodological methods have scrutinized the effectiveness of stock markets. 
In Pakistan there are three stock exchange markets namely: Islamabad stock exchange, Lahore stock exchange and Karachi stock exchange. The last one is the largest and most liquid Stock market of the country. Before this study, a lot of academic literature is available on KSE on the volatility and efficient market hypothesis. But most of the studies cover the time period when the stock market was at boom or having a little business. The main purpose of this study is to test the weak form efficiency (WFE) of Karachi Stock Exchange (KSE), by applying parametric and non-parametric tests. Most of the previous researches only apply one type of test at one time. Furthermore, this study also covers a time period when KSE was recovering it position after 2008 recession. Therefore the research paper will contribute a lot of new things in academic literature of stock markets. The Parametric test includes Augmented Dickey-Fuller (ADF) unit root tests to see the correlation between the values and a Non-Parametric test includes runs test, and Phillips-Perron (PP) unit root test and it is used for investigating the efficiency of the market at the weak level. With the results of this paper an investor can better estimate regarding the weak form efficiency of the market at the time when index is continuously growing. Investors will also be able to understand that whether the existing prices of securities are reflected from the historical trends of the market.

\section{Literature review}

Most of the studies supported the weak efficiency hypothesis; there is only the minority of studies which did not accept the weak form efficiency market hypothesis. The developed markets are originated to be weak form efficient markets (Ansari, 2011). To test the weak form efficiency "runs test" is usually used as it does not need returns to be generally distributed. By testing the random stock prices; we can see the stock market efficiency in its weak form because random stock market prices behaviors supports the weak form efficiency. The test rejects the null hypothesis only, when the expected number of runs is different from the observed number of runs (Ansari, 2011).

The weak form efficiency market hypothesis tests whether the historical share prices can be used to successfully forecast the potential share prices. If the price changes are random (no dependence is found) then this will support the WFEMH, which mean that no investment strategy is based on past prices. On the other hand, if the prices changes are not random (dependence is found) and investment is based on past prices (prices increases in the next stage and contrary) is clearly specify that this can be the base of beneficial investment rule and it will go against the assumptions of the weak-form efficiency market hypothesis (Mobarek \& Keasey, 2000). It has been considered that the past changes in the prices are not supportive because the price changes were random because from the historical changes in prices were not valuable in prediction or estimation of future prices changes particularly; when the cost transaction have done or have taken into the account (Ansari, 2011).

There are three different parametric and non-parametric unit tests are designed to test the null hypothesis: namely, Run Test, Augmented Dickey Fuller test, Phillips-Perron test (Worthington \& Higgs). The unit root test is used to see whether the series is null hypothesis (difference stationery) or the alternative hypothesis (trend stationery) (Al-Jafari, 2011).

The Run test is used to test the statistical independencies between, in this test we don't make any assumptions from where the observations were drawn. Run test is non-parametric test on the basis that if the series of the data is random the observed number of market prices or runs in the series should be near to the expected number of market prices or runs. Augmented Dickey-Fuller tests (ADF) are the most extensively applied tests for unit roots. Phillips-Perron (PP) (1988) tests is the most admired test after that to the Augmented Dickey-Fuller (ADF) tests. The distinction among the PP tests and the ADF tests lies in the behavior of the auto-correlation. The design of the Phillips-Perron (PP) test is to run a non-ADF regression, and then to adjust for the prejudice that might rises because of correlation so that the ADF tables can be used anyway (Al-Jafari, 2011).

In the early study of Indian Stock Exchange and the Kuala Lumpur Stock Exchange the null hypothesis is 
accepted. In Indian stock market, it has been concluded that the returns of Indian Stock Market are random and it supports the weak form efficiency. The stock market of India is based on run tests and other two (Autocorrelation test and LBQ test). The results of BSE (Bombay Stock Exchange) show that out of 200 the 143 returns of stock are insignificant at the $5 \%$ level. So, that the null hypothesis cannot be rejected of the randomness and hence the results illustrate that the Indian Stock Market supports the weak form efficiency market hypothesis (WF-EMH) and the results is not based on past price information (Ansari, 2011). In the study of Kuala Lumpur stock exchange (KLSE), the results indicate that the Kuala Lumpur market is weak-form efficient. The market of Kuala Lumpur used the unit root test, Augmented Dickey Fuller test and by using these tests it is also concluded that there is only 5\% chance that the indices are inefficiently priced (Nassir, Arif, \& Mohamad, 1993)

In the study of Bahrain stock exchange and Palestinian security market and the Dhaka stock market of Bangladesh the null hypothesis has been rejected. In the Bahrain Stock exchange the null hypothesis rejected at the $1 \%$ level of significance and the results shows that the Bahrain stock exchange is inefficient at the weak level. Bahrain Stock market used the unit root test, correlation test and run test to test the weak-form efficiency and implies that by using the historical data of stock market prices the investors will realize the abnormal return (Al-Jafari, 2011). Where in the study of Palestinian security market (PSE) the ADF, PP and run test is used to test the weak-form efficiency and it is concluded from the both parametric and non-parametric tests that the PSE is inefficient at the weak-level and the stock returns in this market are non-random over the period of time. The returns of the 35 sample stock taken to check the weak-form efficiency and it indicated that these PSE at the weak form is inefficient (Awad \& Daraghma, 2009). The results of Dhaka Stock market of Bangladesh indicate that the market is weak form inefficient and rejects the null hypothesis. The run test, autocorrelation test and regression test used to test the weak form efficiency (Mobarek \& Keasey, 2000).

The work done by Haque, Liu, and Fakhar-Un-Nisa, (2011) supported that the Karachi Stock Exchange (KSE) of Pakistan is not weak form efficient because no evidence is founded through the results that by taking higher risk the investors are rewarded. While in the study of Rashid and Husain (2009) it is indicated that the KSE of Pakistan is weak form efficient.

\section{Research methodology}

Pakistan has three stock exchanges, Karachi Stock Exchange, Lahore Stock Exchange and Islamabad Stock Exchange. Karachi Stock exchange being the largest Stock Market of the country is taken for this study. The main objective of this study is to test the Market efficiency of KSE-100 index. The data and values used in this paper are taken from the official website of Karachi Stock exchange. Some softwares like Microsoft Excel and E-views are used for the different calculations and analysis of the data. The values of KSE-100 index are taken on daily basis for a period of two years from 2009-2010. During this period, the market was traded for five days in a week from Monday to Friday. The following three types of tests are used in this research study:

$>\quad$ The Runs Test

$>$ Autocorrelation Function Test

$>\quad$ Unit Root Test

\subsection{The Runs Test}

The Runs test is also known as Wald-Wolfowitz test or Geary test is a non-parametric statistical tool use to verify the randomness hypothesis for a 2-valued data sequence. In other words we can say that the Runs Test is used to check that the element of a sequence is mutually independent. The runs test is significant in determining whether a result of a test is really random, especially in the cases where random against sequential data has inference for subsequent theories. A run is a successive point of series that are either above or below the curve. 
Testing weak form efficiency of capital markets: A case of Pakistan

More precisely we can say that a run is a repeated series of points whose residuals are either all positive or all negative.

\section{Table 1}

Calculations for Runs test

\begin{aligned} \hline Mean $= & 8940.052 \\ \mathrm{R}= & 10.000 \\ \mathrm{n} 0= & 178.000 \\ \mathrm{n} 1= & 317.000 \\ \mathrm{n}= & 495.000 \\ \mathrm{E}(\mathrm{R})= & 228.984 \\ \operatorname{Var}(\mathrm{R})= & 104.754 \\$ StDev $(\mathrm{R})= & 10.235 \\ \mathrm{Z}= & -21.396 \\ \mathrm{p}$-value $= & 0.000 \\ \mathrm{p}$-value $(2$-tailed $)= & 0.000\end{aligned}$

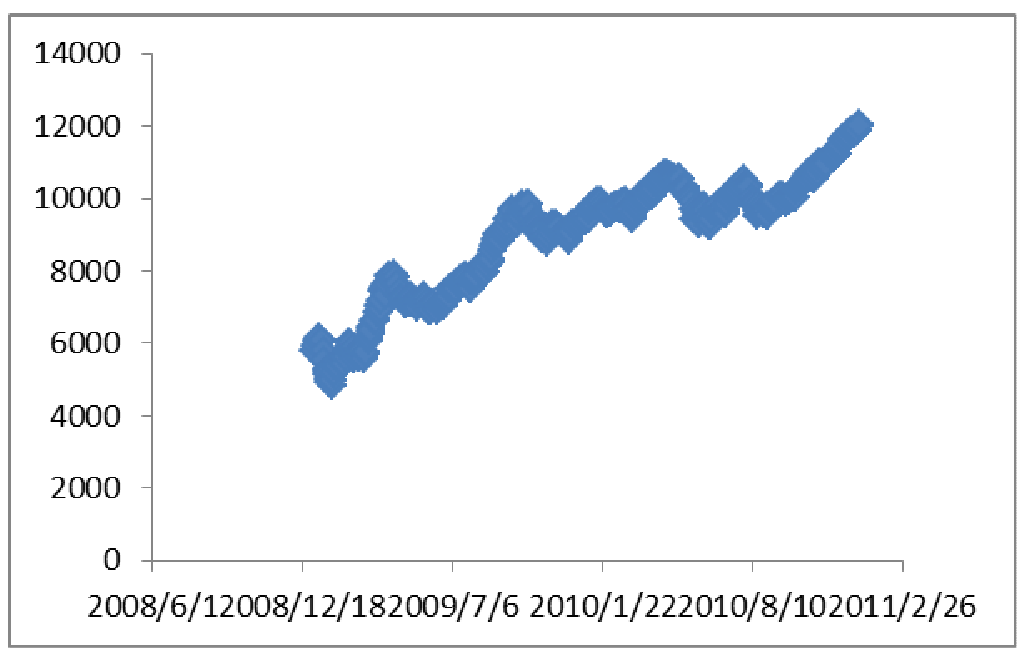

Figure 1. Continuous Growth in KSE

Many researchers have applied the Runs Test to verify the weak form efficiency of the capital markets of different countries. Few of these studies include the Fama (1965), Sharma and Kennedy (1977), Cooper (1982), Chiat and Finn (1983), Wong and Kwong (1984), Yalawar (1988), Ko and Lee (1991), Butler and Malaikah (1992), and Thomas (1995).

With the help of MS Excel, Runs Test is applied on the series of data of KSE Index. The result of this test shows a high $\mathrm{z}$ value which resulted in the zero $\mathrm{p}$-value of the data. The high $\mathrm{z}$ value rejects the weak form efficient hypothesis of the Karachi Stock Exchange and proves that the KSE is a weak form inefficient capital market and there is no randomness in the series of index. The graph also shows a continuous growing trend of the market. This reveals that the future returns can be predicted by using the historical prices.

\subsection{Autocorrelation Function Test}

Autocorrelation is a mathematical illustration of the extent of similarity between a time series and a lagged version of itself over consecutive time periods. It is the same as calculating the correlation among two different time series, apart from that the same time series is used two times, once in its actual form and second as lagged or more time periods. Hence it is also called as "lagged correlation" or "serial correlation". The Autocorrelation Function test is used to know the extent of autocorrelation in a time series. It trial the correlation between the present and lagged observations of the time series of stock returns.

The same can be explained as:

$$
p_{k}=\frac{\sum_{t=1}^{n-k}\left(R_{t}-\bar{R}\right)\left(R_{t+k}-\bar{R}\right)}{\sum_{t=1}^{n}\left(R_{t}-\bar{R}\right)^{2}}
$$

Where $\mathrm{K}=$ Number of lags and $\mathrm{Rt}=$ Real rate of return 
Rehman, S. \& Qamar, M.

Table 2

Autocorrelation Function test

\begin{tabular}{|c|c|c|c|c|c|c|}
\hline Autocorrelation & Partial Correlation & & $\mathrm{AC}$ & PAC & Q-Stat & Prob \\
\hline. $\mid * * * * * * * *$ &. $\mid * * * * * * * *$ & 1 & 0.983 & 0.983 & 481.58 & 0.000 \\
\hline.$|* * * * * * *|$ & $.1 . \quad 1$ & 2 & 0.967 & 0.013 & 948.64 & 0.000 \\
\hline.$|* * * * * * *|$ & .l. & 3 & 0.952 & 0.003 & 1401.7 & 0.000 \\
\hline.$|* * * * * * *|$ & .I. & 4 & 0.937 & 0.008 & 1841.5 & 0.000 \\
\hline.$|* * * * * * *|$ & .l. & 5 & 0.921 & -0.021 & 2267.6 & 0.000 \\
\hline.$|* * * * * * *|$ &. & 6 & 0.906 & 0.007 & 2680.9 & 0.000 \\
\hline.$|* * * * * * *|$ &.. & 7 & 0.891 & -0.001 & 3081.5 & 0.000 \\
\hline.$|* * * * * * *|$ & .l. & 8 & 0.876 & -0.033 & 3469.1 & 0.000 \\
\hline.$|* * * * * * *|$ & .l. & 9 & 0.860 & -0.004 & 3843.8 & 0.000 \\
\hline.$|* * * * * * *|$ &. & 10 & 0.845 & -0.011 & 4205.8 & 0.000 \\
\hline.$|* * * * * *|$ & .l. & 11 & 0.829 & -0.004 & 4555.5 & 0.000 \\
\hline.$|* * * * * *|$ &. & 12 & 0.814 & -0.002 & 4893.1 & 0.000 \\
\hline.$|* * * * * *|$ & .l. & 13 & 0.799 & -0.015 & 5218.7 & 0.000 \\
\hline.$|* * * * * *|$ &. & 14 & 0.783 & -0.020 & 5532.2 & 0.000 \\
\hline.$|* * * * * *|$ &.. & 15 & 0.768 & 0.007 & 5834.2 & 0.000 \\
\hline.$|* * * * * *|$ &.. & 16 & 0.752 & -0.007 & 6125.0 & 0.000 \\
\hline.$|* * * * * *|$ &. & 17 & 0.737 & 0.001 & 6404.9 & 0.000 \\
\hline.$|* * * * * *|$ &.. & 18 & 0.724 & 0.025 & 6675.0 & 0.000 \\
\hline.$|* * * * * \quad|$ & .l. & 19 & 0.711 & 0.023 & 6936.2 & 0.000 \\
\hline.$|* * * * * \quad|$ &.. & 20 & 0.698 & 0.008 & 7188.8 & 0.000 \\
\hline.$|* * * * * \quad|$ &. & 21 & 0.686 & -0.005 & 7433.0 & 0.000 \\
\hline.$|* * * * * \quad|$ & .l. & 22 & 0.674 & 0.005 & 7669.3 & 0.000 \\
\hline. $\mid * * * * *$ & .l. & 23 & 0.663 & 0.010 & 7898.1 & 0.000 \\
\hline.$|* * * * * \quad|$ & .l. & 24 & 0.652 & 0.018 & 8120.0 & 0.000 \\
\hline. $\mid * * * * *$ &.. & 25 & 0.641 & -0.017 & 8334.9 & 0.000 \\
\hline.$|* * * * * \quad|$ & . I. & 26 & 0.630 & -0.011 & 8542.8 & 0.000 \\
\hline.$|* * * * * \quad|$ & .l. & 27 & 0.619 & -0.004 & 8743.9 & 0.000 \\
\hline. $\mid * * * * *$ & .l. & 28 & 0.608 & 0.022 & 8938.9 & 0.000 \\
\hline.$|* * * * * \quad|$ & . I. & 29 & 0.599 & 0.031 & 9128.6 & 0.000 \\
\hline. $\mid * * * * *$ & .l. & 30 & 0.590 & -0.013 & 9312.9 & 0.000 \\
\hline. $\mid * * * *$ &. & 31 & 0.581 & -0.011 & 9491.8 & 0.000 \\
\hline. $\mid * * * *$ & .I. & 32 & 0.572 & 0.011 & 9665.7 & 0.000 \\
\hline. $\mid * * * *$ & .I. & 33 & 0.564 & 0.007 & 9834.9 & 0.000 \\
\hline. $\mid * * * *$ & . I. & 34 & 0.555 & -0.009 & 9999.2 & 0.000 \\
\hline. $\mid * * * *$ &. & 35 & 0.546 & -0.007 & 10159. & 0.000 \\
\hline $.1 * * * *$ &. & 36 & 0.537 & -0.021 & 10313. & 0.000 \\
\hline
\end{tabular}

Note. Sample: 1,495. Included observations: 495

The daily data of the stock market index is used to calculate ACF. The data is collected in MS excel sheet and the test is performed by using E-views. The above results show the correlograms of the autocorrelation and partial correlation function on stock market index during 2009-10.

The above shown results reveal that a positive autocorrelation exist in the daily returns of the Karachi Stock Exchange during 2009-10. The positive correlation indicates the non-randomness in the returns. The future returns can be predicted by following this continuous positive correlation in the series of data. Hence the Efficient Market Hypothesis is again rejected. The results of Autocorrelation Function test and Runs test of daily stocks are alike in a way that both tests fabricate a positive autocorrelation.

\subsection{Unit Root Test}

The Unit Root test was first developed by two statisticians D. A. Dickey and W. A. Fuller in 1979 hence is also called the Dickey-Fuller test. In econometrics the augmented version of Dickey-Fuller test is commonly used because of its applicability on larger and more complex set of time series models. In a more precise way we can say that Augmented Dickey-Fuller (ADF) test is a test for a unit root in a given time series. ADF in a test is a 
Testing weak form efficiency of capital markets: A case of Pakistan

negative number, more the negativity of the number, stronger are the chances to reject the hypothesis that there is a unit root at some confidence level.

\section{Table 3}

\section{Unit Root test}

Null Hypothesis: SERIES01 has a unit root

Exogenous: Constant

Lag Length: 0 (Automatic based on SIC, MAXLAG=17)

\begin{tabular}{lccc}
\hline & & t-Statistic & Prob. $^{*}$ \\
\hline \multicolumn{2}{l}{ Augmented Dickey-Fuller test statistic } & -0.804824 & 0.8165 \\
\hline Test critical values: & $1 \%$ level & -3.443361 & \\
& $5 \%$ level & -2.867171 & \\
& $10 \%$ level & -2.569831 & \\
\hline
\end{tabular}

Note. *MacKinnon (1996) one-sided p-values.

\section{Table 4}

Augmented Dickey-Fuller test

Augmented Dickey-Fuller Test Equation

Dependent Variable: D(SERIES01)

Method: Least Squares

Sample (adjusted): 2495

Included observations: 494 after adjustments

\begin{tabular}{lcccc}
\hline Variable & Coefficient & Std. Error & t-Statistic & Prob. \\
\hline SERIES01(-1) & -0.002470 & 0.003069 & -0.804824 & 0.4213 \\
C & 34.67735 & 27.88043 & 1.243788 & 0.2142 \\
\hline R-squared & 0.001315 & Mean dependent var & 12.60911 \\
Adjusted R-squared & -0.000715 & S.D. dependent var & 112.1152 \\
S.E. of regression & 112.1553 & Akaike info criterion & 12.28169 \\
Sum squared resid & 6188775. & Schwarz criterion & 12.29870 \\
Log likelihood & -3031.577 & F-statistic & 0.647741 \\
Durbin-Watson stat & 1.895122 & Prob(F-statistic) & 0.421310 \\
\hline
\end{tabular}

Alike the ACF test, the stock market data of KSE-100 index in ADF test is also taken on daily basis for a period of two years from 2009-10. The data collected from KSE website in the form of MS excel sheet used to perform the test in E-views.

As shown in the above results, the value of ADF is less than the Critical Values at all three significant levels. This concludes that there exist a Unit Root and hence the series of KSE returns is non-stationary and continuously growing. As the Market returns are growing with the passage of time, so the future values of the returns can also be predicted in case of KSE. This confirms that the KSE is an inefficient Capital Market and thus the Random Walk Hypothesis is again rejected.

\section{Conclusion}

The current research study adds to enduring debate on weak form efficiency of Pakistani stock markets. This research article uses the latest daily data of KSE 100-Index over a period of two years from 2009 to 2010 . In order to analyze the weak form efficient hypothesis, the study uses different types of tests. Instead of relying on a single experiment, the study rather applied different econometric tests to verify the weak form efficiency of the Pakistani Stock Market.

In view of the above stated facts based on the estimated results it is concluded the weak form efficient hypothesis does not seize true in the Pakistani stock markets scenario. All the three tests give the similar results that the Market is continuously growing and have a positive correlation in the returns and also a lower ADF value at any significant level. Hence the market shows an inefficient trend. The study is also in lines with the 
results of Islam, (2005), Haque, Liu, and Fakhar-Un-Nisa, (2011) and Hameed and Ashraf (2006) who concluded that the hypothesis of weak form efficiency does not stand true in Pakistani Stock Markets. In future, the studies can be conducted by using data of different years from Pakistani Stock Markets and by applying different statistical and econometrics methods like Phillips-Person test, KPSS test and Autoregressive models developed by John Denis Sargan and Alok Bhargava. It is also essential to expand more deep into the procedures and characteristics of the stock market of Pakistan in terms of its efficiency and the assessment processes to make an informed evaluation of the empirical characteristics of the Pakistani Stock market.

\section{References}

Al-Jafari, M. K. (2011). Testing the weak-form efficiency of Bahrain securities market. International Research Journal of Finance and Economics, 72, 14-24.

Awad, I., \& Daraghma, Z. (2009). Testing the weak-form efficiency of the Palestinian securities market. International Research Journal of Finance and Economics, 32, 7-17.

Butler, K. C., \& Malaikah, S. J. (1992). Efficiency and inefficiency in thinly traded Stock Markets: Kuwait and Saudi Arabia. Journal of Banking and Finance, 16, 97-201. http://dx.doi.org/10.1016/0378-4266(92)90085-E

Chiat, H. S., \& Finn, F. J. (1983). Random walks on the stock exchange of Singapore. Accounting and Finance, 23, 81-87. http://dx.doi.org/10.1111/j.1467-629X.1983.tb00044.x

Cooper, J. C. B. (1982). World stock markets: Some random walk tests. Applied Economics, 14, 515-531. http://dx.doi.org/10.1080/00036848200000046

Fama, E. (1965). The behavior of stock market prices. Journal of Business, 38(1), 34-105. http://dx.doi.org/10.1086/294743

Fama. E. (1970). Efficient capital markets: A review of theory and empirical work. Journal of Finance, 25, 383-417. http://dx.doi.org/10.2307/2325486

Hameed, A., \& Ashraf, H. (2006). Stock market volatility and weak-form efficiency: Evidence from an emerging market. The Pakistan Development Review, 45(4), 1029-1040.

Haque, A., Liu, H. C., \& Fakhar-Un-Nisa. (2011). Testing the weak form efficiency of Pakistani stock market 2000-2010. International Journal of Economics and Financial Issues, 1(4), 153-162.

Hussain, F., Hamid, K., \& Khan, R. S. (2011). Day of the week effect and stock returns: Evidence from Karachi stock exchange Pakistan. Far East Journal of Psychology and Business, 3(1), 25-31.

Islam, S., Watanapalachaikul, S., \& Clark, C. (2005). Are emerging financial market efficient? Some evidence from the models of the Thai stock market. Financial modeling program centre for strategic economic studies. Melbourne, Australia: Victoria University.

Ko, K. S., \& Lee, S. B. (1991). A comparative analysis of the daily behavior of stock returns: Japan, the US and the Asian NICs. Journal of Business Finance and Accounting, 18, 219-234. http://dx.doi.org/10.1111/j.1468-5957.1991.tb00590.x

Mobarek, A., \& Keasey, K. (2000). Weak form market efficiency of an emerging market: Evidence from Dhaka stock market of Bangladesh. Conference of the European Network for Bangladesh Studies. Oslo, Norway.

Nassir, A. M., Arif, A., \& Mohamad, S. (1993). Weak-form efficiency of the Kuala Lumpur stock exchange: An application of unit root analysis. Pertanika Journal of Social Sciences \& Humanities, 1(1) 57-62.

Rashid, A., \& Hussain, F. (2009). Testing the weak form efficiency in Pakistan's equity, badla and money markets. MPRA Paper. Munich, Germany: University Library of Munich.

Sharma, J. L., \& Kennedy, R. E. (1977). A comparative analysis of stock price behavior on the Bombay, London and New York stock exchanges. Journal of Financial and Quantitative Analysis, 12, 391-413. http://dx.doi.org/10.2307/2330542

Spate, U., \& Ansari, V. (2011). Testing weak form stock market efficiency on Bombay stock exchange of India. Tenth International Conference on Operations and Quantitative Management (pp. 229-233). Nashik, India. 
Testing weak form efficiency of capital markets: A case of Pakistan

Thomas, S. (1995). An empirical characterization of the Bombay stock exchange. Center for Monitoring Indian Economy. California, USA: University of Southern California.

Wong, K. A., \& Kwong, K. S. (1984). The behavior of Hong Kong stock prices. Applied Economics, 16, 905-917. http://dx.doi.org/10.1080/00036848400000059

Worthington, A. C., \& Higgs, H. (2004). Random walks and market efficiency in European equity markets. Global Journal of Finance and Economics, 1(1), 59-78.

Yalawar, Y. B. (1988). Bombay stock exchange: Rates of return and efficiency. Indian Economic Journal, 35, 68-121. 
Rehman, S. \& Qamar, M. 